Research Article

\title{
The Variation Mechanism of Thermal Properties of Loess with Different Water Contents during Freezing
}

\author{
Xihao Dong $\mathbb{D}^{\mathbb{D}}$, Shuai Liu $\mathbb{D}^{\mathbb{D}}$, and Yuanxiang Yu \\ School of Architecture and Civil Engineering, Xi'an University of Science and Technology, Xi'an 710054, Shaanxi, China \\ Correspondence should be addressed to Xihao Dong; dongxh@xust.edu.cn
}

Received 15 March 2021; Accepted 10 May 2021; Published 20 May 2021

Academic Editor: Weerachart Tangchirapat

Copyright ( $\odot 2021$ Xihao Dong et al. This is an open access article distributed under the Creative Commons Attribution License, which permits unrestricted use, distribution, and reproduction in any medium, provided the original work is properly cited.

\begin{abstract}
The thermal properties of soils are affected by many factors, such as temperature, water content, and structure. Based on the transient plane source method of thermal physics, the thermal properties of loess with different water content during the freezing process were tested. We analyzed the variation mechanism of thermal properties from the perspective of phase change. Based on the Pore/Particle and Crack Analysis System (PCAS) and theory of heat transfer, we then analyzed the microstructure and heat conduction process of loess. And a calculation model of volumetric heat capacity of frozen soil was presented. The results show that, in the major phase transition zone, the variation of the thermal properties of loess with temperature is the most significant. And the thermal diffusivity increases sharply with the significant increase of thermal conductivity and the rapid decrease of volumetric heat capacity. Moisture content not only increases the thermal conductivity and volume heat capacity of loess but also makes the influence of temperature on the thermophysical parameters more significant. The effect of temperature on thermal properties is mainly due to the change of heat transfer media caused by phase transition of water-ice, followed by the change of thermal properties of heat transfer media such as soil particles, water, ice, and air with temperature. Increasing the water content reduces the contact thermal resistance between soil particles because of the increase in the thickness of the water film on the surface of soil particles and the thermal conductivity of the heat transfer medium between particles, thus changing the thermal properties of soils.
\end{abstract}

\section{Introduction}

The engineering properties of soils can change under the influence of the external environment. For example, changes in temperature and moisture content of soils often lead to frost heave and thaw settlement, which can lead to a series of engineering diseases [1-4]. Freeze-thaw disasters are closely related to water migration [5], heat storage, and energy exchange in soils and are affected by thermal properties of soils [6]. In the last few decades, the fixed value of thermal properties is used when we carry out thermal calculations of engineering in cold regions, without considering the change of thermal properties affected by temperature in the process of heat transfer in soils, which leads to the low accuracy of calculation results. Therefore, obtaining the exact thermal properties of soils at different temperatures is the key for engineering calculation.
According to previous studies, factors affecting the thermal properties of soils can be roughly divided into two categories: (1) internal factors, such as soil fabric (e.g., mineral composition, particle shape, and particle size) and soil structure (e.g., porosity, gradation, and pore-size distribution), and water content; (2) external factors, such as temperature [7-12]. A large number of scholars have studied the effects of these factors on the thermal properties of the soil. Xu et al. [3] and Zhang et al. [13] found the relationships between the thermal conductivity of a silty clay and various influence factors during a freezing-thawing process. Zhen et al. [14] analyzed the effects of dry density and water content on the thermal conductivities of remolded loess and undisturbed loess. Ivan V. Nikolaev et al. [15] completed the test of thermal conductivity of sand, for temperatures ranging from $2^{\circ} \mathrm{C}$ to $92^{\circ} \mathrm{C}$ and water contents varying from complete dryness to full saturation. Xiao et al. [16] analyzed 
the effect of particle size gradation on the thermal conductivity of carbonate sands. Jia et al. [17] analyzed the responses of soil moisture and thermal conductivity to precipitation in the mesa of the Loess Plateau. BarryMacaulay et al. [18] researched the moisture content, density, mineralogical composition, and particle size of soils in Melbourne (Australia). Cai et al. [19] analyzed the relationship between the soil thermal resistivity and moisture content at different dry densities. Moreover, the effects of ice, frozen and unfrozen state, and freezing-thawing process have also been investigated [13, 20-23]. Kojima et al. [24] tested thermal conductivity and volumetric heat capacity of partially frozen soils with a dual probe heat pulse (DPHP) sensor. Rasmussen et al. [4] measured the thermal conductivity of different gravimetric water/ice contents in frozen and thawed permafrost.

However, investigations on the thermal properties of unfrozen soil are more than those of frozen soil, and most of them only involve thermal conductivity, not the volumetric heat capacity and the thermal diffusivity. Most of the studies on the thermal properties of frozen soil are based on the effect of water-ice phase transition on them, while neglecting the effect of temperature on the thermal physical properties of soil components.

Based on experimental tests, some scholars have established theoretical models of thermal properties from the statistical or empirical perspective [20,25-28]. Theoretical estimates of the effective volumetric heat capacity of frozen layers of sandy soil in Yakutsk are established by Neradovskii [29]. Tu et al. [30] presented the weighted arithmetic mean model of the volumetric heat capacity and two kinds of methods that evaluate the soil thermal diffusivity. Tarnawski and Leong [31] developed a geometric mean model for predicting the effective thermal conductivity of unsaturated soils. Li et al. [32] researched thermal conductivity of soils based on the least-squares finite element method. Lipiec et al. [33] researched thermal conductivity and heat capacity using a statisticalphysical model and formulae of de Vries, respectively. Based on the Fourier series boundary conditions for soil surface temperature, $\mathrm{Hu}$ et al. [34] established the separation of variables for the heat conduction-convection equation. Comparing the test results of the thermal conductivity of sand, Zhang et al. [35] analyzed the prediction accuracy of the three alternative soil thermal conductivity predictive models. Côté and Konrad [36] developed a generalized thermal conductivity model for moist soils that is based on the concept of normalized thermal conductivity with respect to dry and saturated states. However, the prediction accuracy and applicability of these models need to be further verified, and most of the parameters in these models have no specific physical meaning. The effect of water-ice phase transition on thermal conductivity of soil during temperature change cannot be fully explained from the perspective of thermal physics. Based on the theory of heat transfer and considering the composition and microstructure of soils, the model that can explain the mechanism of thermal conductivity with temperature changes is rare.
TABle 1: Physical properties of loess.

\begin{tabular}{lc}
\hline Property & Value \\
\hline Water content $w(\%)$ & 13.23 \\
Dry density $\rho_{d}\left(\mathrm{~g} / \mathrm{cm}^{3}\right)$ & 1.32 \\
Saturation $S(\%)$ & 33.95 \\
Porosity ratio $e$ & 1.06 \\
Plastic limit $w_{P}(\%)$ & 20.6 \\
Liquid limit $w_{L}(\%)$ & 31.2 \\
Specific gravity of soil particle $G_{s}$ & 2.72 \\
\hline
\end{tabular}

Based on the transient plane source method, the thermophysical properties of loess at different temperatures were measured. The variation of thermal properties during the freezing of loess was studied, and the mechanism of the variation was analyzed from the point of view of phase change. Based on the theory of heat transfer, the heat conduction process of dry soil, wet soil, and frozen soil was analyzed from the perspective of soil composition and microstructure. The calculation model of the specific heat capacity of frozen soils was presented.

\section{Laboratory Tests}

2.1. Specimen Preparation. The loess used in this study was the undisturbed Malan loess of Yan'an in NW China, which is yellow. The soil was taken at a depth of $2.8 \mathrm{~m}$ and below the local frozen soil layer. The physical properties of loess used are shown in Table 1. The tested soil is classified as CL based on USCS.

The undisturbed samples collected in the field were prepared with a diameter of $61.8 \mathrm{~mm}$ and a height of $140 \mathrm{~mm}$. The water content $(w)$ of the sample was changed by natural drying and artificial humidification to $0 \%, 3 \%$, $8 \%, 12 \%$, and $18 \%$. After the water of these samples was uniformly diffused, they were cut into small samples with a diameter of $50 \mathrm{~mm}$ and a height of $40 \mathrm{~mm}$.

\subsection{Testing System and Procedure. A Hot Disk TPS $2500 \mathrm{~S}$} Thermal Constants Analyzer supplied by Hot Disk, Göteborg, Sweden (Figure 1), was used to measure thermal properties of loess. The instrument's operating temperature $(T)$ range is -10 to $1000 \mathrm{~K}$. Two similar samples were required for each group to meet the requirements of the transient plane source (TPS) method, since both sides of the test probe need to be in close contact with the surface of soil samples. The instrument can accurately test the thermal conductivity and specific heat capacity of the soil. Then the thermal diffusivity of samples can be obtained by calculation. The high-low temperature test chamber provided a constant low $T$ environment for soil samples. The circumstance $T$ was changed step by step during freezing of soil samples, namely, $30^{\circ} \mathrm{C}, 20^{\circ} \mathrm{C}, 10^{\circ} \mathrm{C}, 5^{\circ} \mathrm{C}, 0^{\circ} \mathrm{C},-0.5^{\circ} \mathrm{C},-1^{\circ} \mathrm{C},-2^{\circ} \mathrm{C}$, $-3^{\circ} \mathrm{C},-5^{\circ} \mathrm{C},-10^{\circ} \mathrm{C},-15^{\circ} \mathrm{C},-20^{\circ} \mathrm{C}$, and $-30^{\circ} \mathrm{C}$. The initial state variables and thermal properties of soil samples are shown in Table 2.

\section{Experimental Results and Analysis}

3.1. Effect of Temperature on Thermal Properties of Loess. Figure 2 shows the thermal characteristics of loess during freezing. It can be seen from Figure 2 that the thermal 


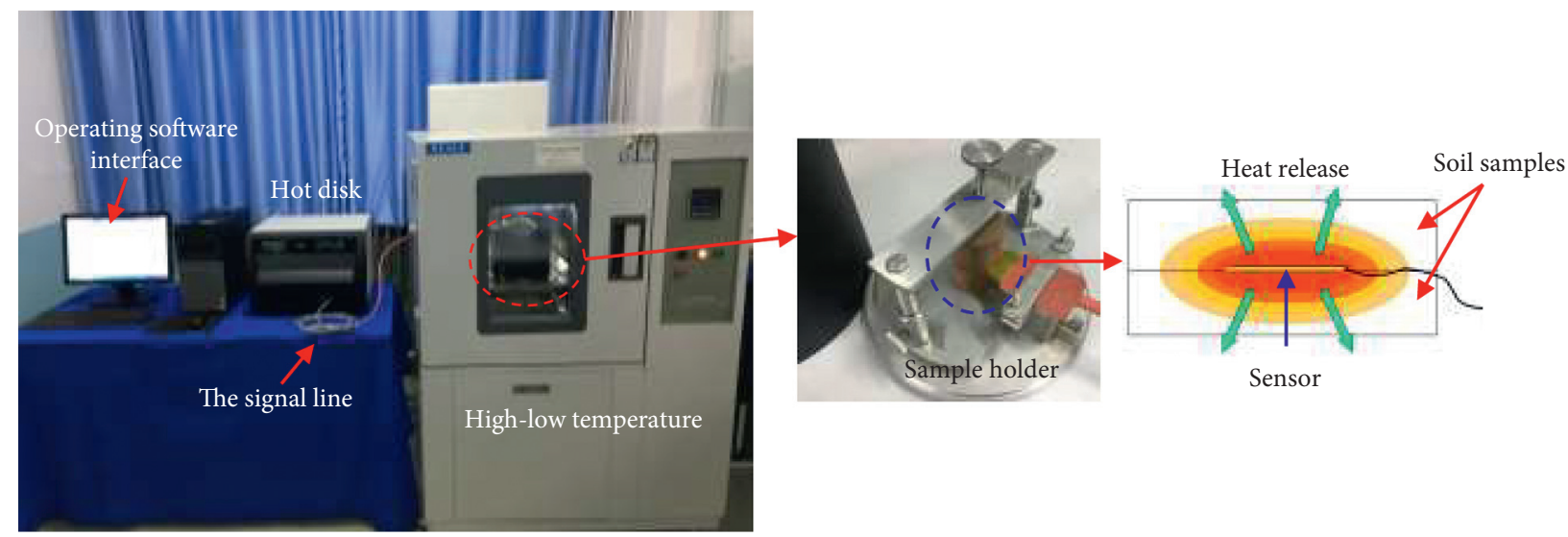

FIgURE 1: Diagram of the experimental system.

TAвLE 2: Initial state variables and thermal properties of soil samples.

\begin{tabular}{lcccccc}
\hline Specimen & $\begin{array}{c}\text { Density } \\
\left(\mathrm{kg} / \mathrm{m}^{3}\right)\end{array}$ & $\begin{array}{c}\text { Water content } \\
(\%)\end{array}$ & $\begin{array}{c}\text { Degree of } \\
\text { saturation }(\%)\end{array}$ & $\begin{array}{c}\text { Thermal conductivity } \\
(\mathrm{W} / \mathrm{m} / \mathrm{K})\end{array}$ & $\begin{array}{c}\text { Volumetric heat capacity } \\
\left(\mathrm{MJ} / \mathrm{m}^{3} / \mathrm{k}\right)\end{array}$ & $\begin{array}{c}\text { Thermal diffusivity } \\
(\mathrm{mm} / \mathrm{s})\end{array}$ \\
\hline $\mathrm{U} 1$ & 1.320 & 0 & 0 & 0.747 & 0.87 & 0.6505 \\
$\mathrm{U} 2$ & 1.360 & 3 & 7.70 & 0.866 & 1.122 & 0.7718 \\
$\mathrm{U} 3$ & 1.426 & 8 & 20.53 & 1.071 & 1.401 & 0.7645 \\
$\mathrm{U} 4$ & 1.478 & 12 & 30.79 & 1.206 & 2.051 & 0.7408 \\
$\mathrm{U} 5$ & 1.558 & 18 & 46.19 & 1.498 & & 0.7304 \\
\hline
\end{tabular}

properties of loess show a certain regularity with $T$, which can be roughly divided into three stages (Figure 3 ). The first stage (stage I) can be regarded as the period Tabove $0^{\circ} \mathrm{C}$, and thermal conductivities and volume heat capacities increase slightly, while thermal diffusivities are reversed. In the water-ice phase transition zone $\left(0^{\circ} \mathrm{C}>T \geq-3^{\circ} \mathrm{C}\right)$, the thermal properties of loess change drastically (stage II). The thermal diffusivity increases sharply with the significant increase of thermal conductivity $(\lambda)$ and the rapid decrease of volumetric heat capacity. In the frozen state $\left(\mathrm{T}<-3^{\circ} \mathrm{C}\right)$, thermal properties change slowly with $T$ (stage III).

The thermal properties of the soil are mainly determined by the thermal properties of soil particles, water, and air. With the decrease of $T\left(T \geq 0^{\circ} \mathrm{C}\right)$, the thermal resistance of soil particles decreases because of the slow thermal motion of the mineral molecules and the decrease of the amplitude of the lattice vibration. In addition, the decrease of $T$ leads to the shrinkage of soil particle volume, the increase of density, and the decrease of thermal contact resistance. Therefore, the thermal properties of soils change slightly in this stage. When $T$ is below $0{ }^{\circ} \mathrm{C}$, the freezing process of soils can be divided into three stages [3, 37-39]: (1) when $T$ is above the freezing point, soils are still in unfrozen states; thus, the thermal properties of soils are hardly changing; (2) when $T$ drops to the freezing point of soils, ice crystal nuclei appear in the pores and increase rapidly. As a large number of water molecules accumulate on ice crystal nuclei, ice crystals and ice crystal grains are formed. The sharp phase transition of water-ice causes a rapid increase in the amount of ice and a rapid decrease in the amount of water. Due to changes of heat transfer media and their content, the thermal properties of soils change rapidly. (3) In the frozen state $\left(T<-3^{\circ} \mathrm{C}\right)$, most of the water has been transformed into ice, which plays a major role in heat conduction between soil particles. In this stage, there are two reasons for the slight change of thermal properties: the phase transition of a small amount of water and the change of thermal properties of the ice.

The influence of $T$ on the thermal properties of the soil can also be reflected from the thermal properties of soil constituents and their variation with $T$. The thermal conductivity of water is about $1 / 4$ of that of ice and decreases with the decrease of $T$, while that of ice is on the contrary (Figure 4). This phenomenon can scientifically explain the change of thermal conductivities before and after freezing of soils in Figure 2(a). The volumetric heat capacity of the soil particles at room $T$ is $1.6 \mathrm{MJ} / \mathrm{m}^{3} / \mathrm{K}$ to $2.2 \mathrm{MJ} / \mathrm{m}^{3} / \mathrm{K}$, and that of water is $4.175 \mathrm{MJ} / \mathrm{m}^{3} / \mathrm{K}$. However, the volumetric heat capacity of the air is $1.206 \times$ $10^{-3} \mathrm{MJ} / \mathrm{m}^{3} / \mathrm{K}$, which is too small to be negligible. In the unfrozen state $\left(T \geq 0^{\circ} \mathrm{C}\right)$, the volumetric heat capacity of water increases slightly with $T$. The volumetric heat capacity of ice is smaller than that of water and decreases rapidly with $T$. As shown in Figure 4, the volumetric heat capacity value of water (or ice) is maximum at the $T 0^{\circ} \mathrm{C}$. Therefore, the volumetric heat capacity of loess rapidly decreases during freezing, and the value is maximum at the $T 0^{\circ} \mathrm{C}$ (Figure 2(b)). In addition, the volumetric heat capacity of loess in the frozen state $\left(T<-3^{\circ} \mathrm{C}\right)$ is smaller than that in the unfrozen state $\left(T \geq 0^{\circ} \mathrm{C}\right)$. The thermal diffusivity of water at room $T$ is $0.143 \mathrm{~mm}^{2} / \mathrm{s}$ and decreases with $T$ (Figure 4 ). The thermal diffusivity of ice at the $T 0^{\circ} \mathrm{C}$ is $1.15 \mathrm{~mm}^{2} / \mathrm{s}$ and increases with $T$. Therefore, the thermal diffusivities of unfrozen soils decrease with $T$, while the frozen soils are reversed (Figure 2(c)). 


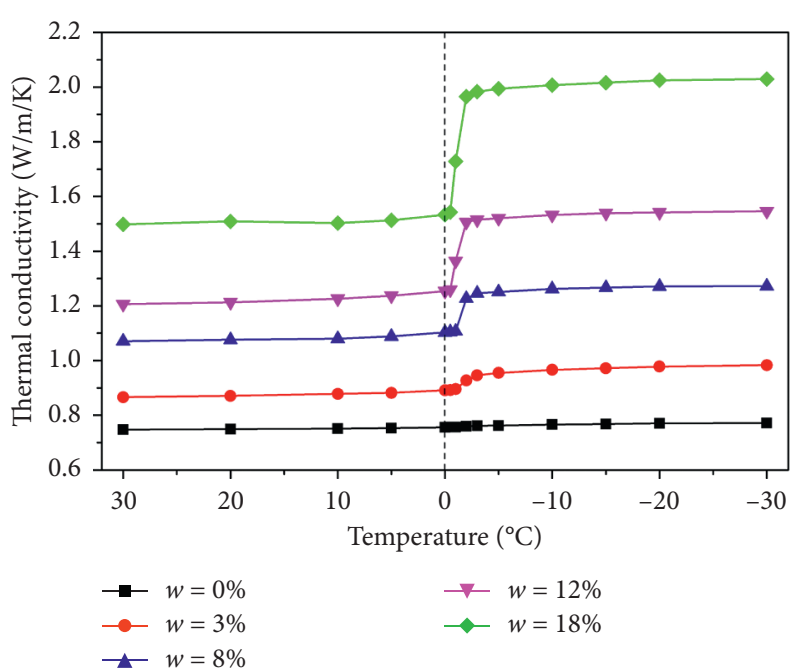

(a)

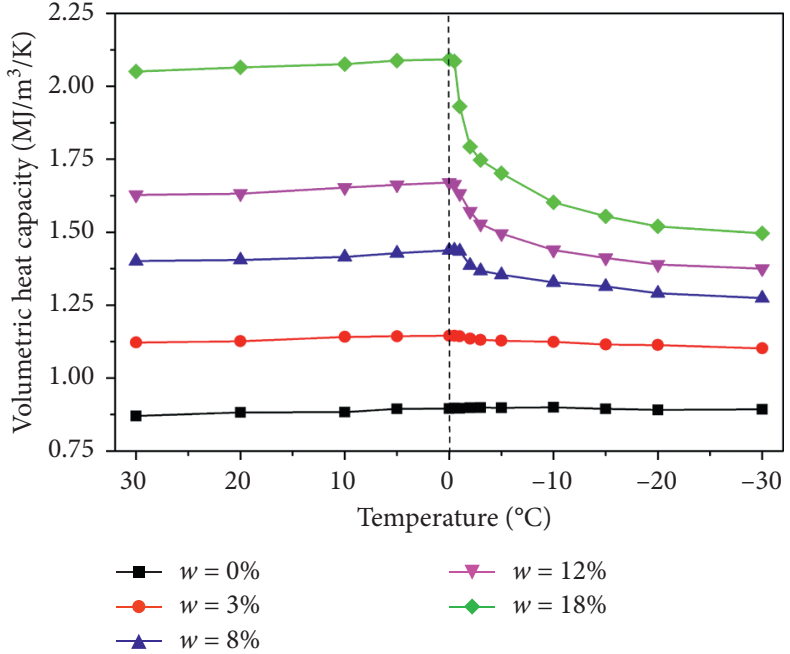

(b)

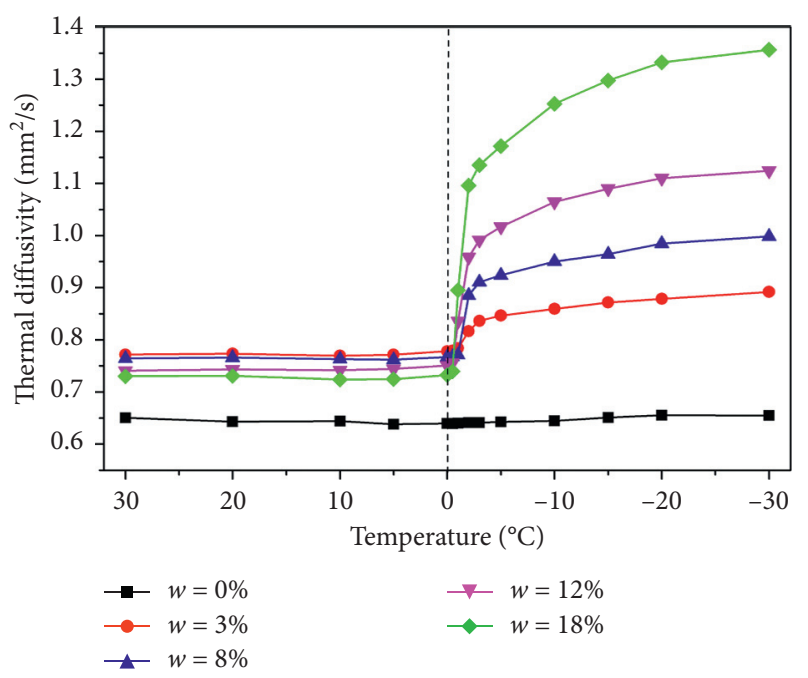

(c)

FIgURE 2: Variations of the thermal properties of loess with the (T) and (w). (a) Thermal conductivity, (b) volumetric heat capacity, and (c) thermal diffusivity.

As presented in the above analysis, the influence of $T$ on thermal properties of the soil is mainly because of the phase transition of water-ice, followed by the change of thermal properties of heat transfer media such as soil particles, water, ice, and air with $T$.

\subsection{Effect of Water Content on Thermal Properties of Soils.} The contribution of water to the thermal physical properties of the soil not only depends on the water content but also is closely related to the state of pore water. As can be seen from Figures 5(a) and 5(b), the larger the water content, the greater the thermal conductivity and volumetric heat capacity and the more significant the influence of $T$ on them. For example, when $T$ falls from $0^{\circ} \mathrm{C}$ to $10^{\circ} \mathrm{C}$, the increment of thermal conductivity of $0.010,0.075,0.159,0.278$, and $0.474 \mathrm{~W} / \mathrm{m} / \mathrm{K}$ and the decrease of volumetric heat capacity of $0.005,0.021,0.110,0.231$, and $0.491 \mathrm{MJ} / \mathrm{m}^{3} / \mathrm{K}$ were measured for $w$ of $0,3,8,12$, and $18 \%$. Figure 5 (c) shows that the larger the water content, the smaller the thermal diffusivity of soils at room $T$ and the greater the effect of $T$ on it. Through analysis, we believe that the main reasons are as follows:

(1) The soil with low water content mainly relies on soil particles and air for heat conduction, while the soil with high water content mainly relies on soil particles and water. The thermal conductivities of soil particles at room $T$ vary from $2.0 \mathrm{~W} / \mathrm{m} / \mathrm{K}$ to $7.7 \mathrm{~W} / \mathrm{m} / \mathrm{K}$. The thermal conductivity of water is $0.61 \mathrm{~W} / \mathrm{m} / \mathrm{K}$, and that of air is $0.026 \mathrm{~W} / \mathrm{m} / \mathrm{K}$ [31]. The increase of pore water increases the thickness of water film on the surface of soil particles and the thermal conductivity of heat transfer medium between soil particles. It can be considered that the increase of water content reduces the contact thermal resistance between soil particles. Therefore, 


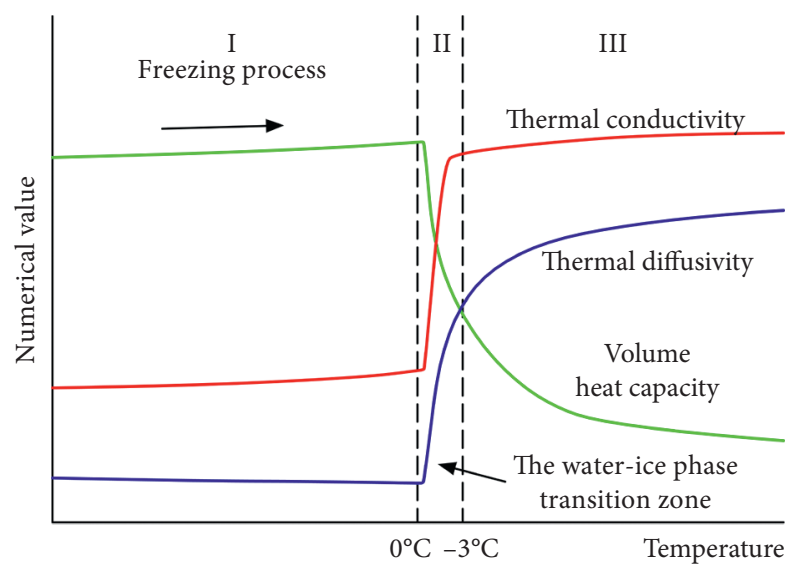

Figure 3: Schematic diagram of the thermal properties of loess as a function of $(\mathrm{T})$ during freezing.

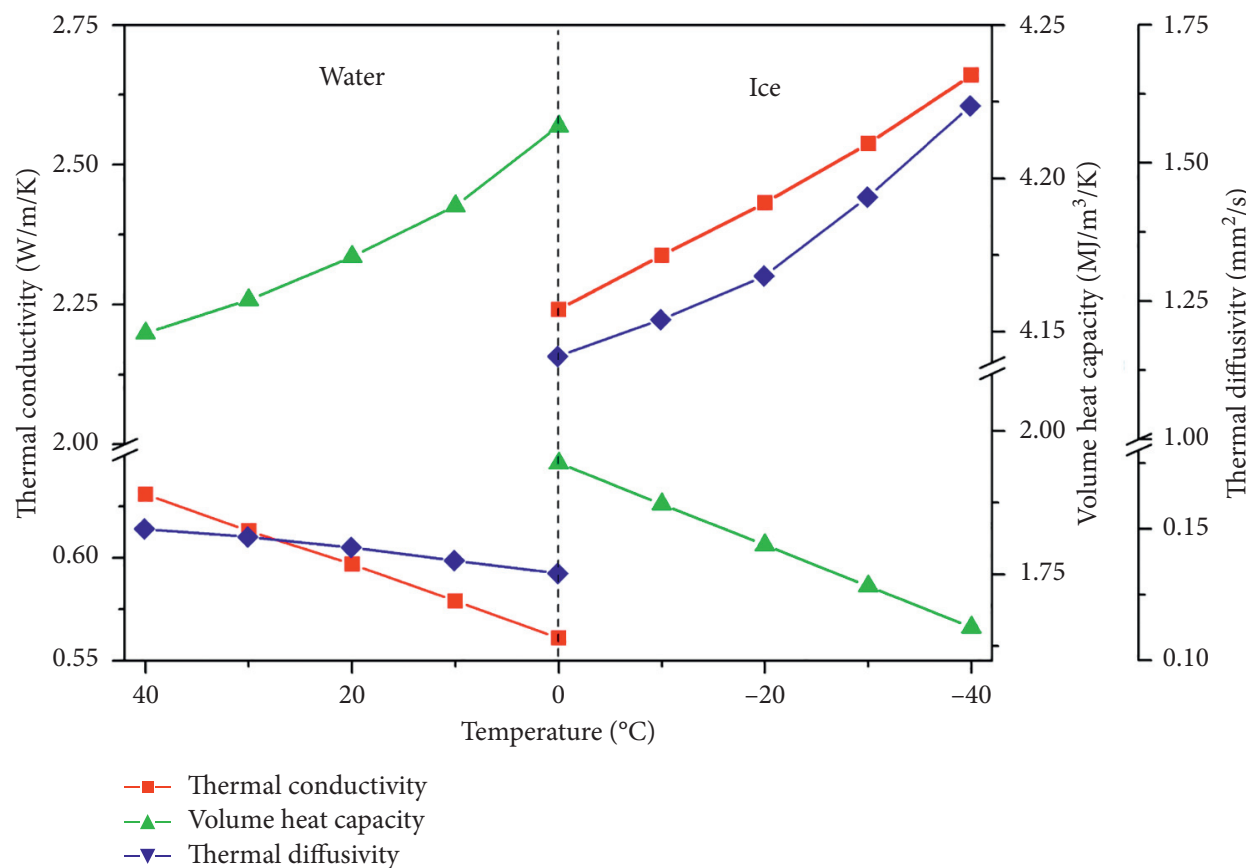

FIgURE 4: Variations of thermal properties of water and ice with the temperature.

the thermal conductivity of soils with high water content is larger than that of soils with low water content. For the frozen soil, the higher the water content, the higher the ice content and the larger the thermal conductivity (Figure 5(a)).

(2) Increasing the water content increases the volumetric heat capacity of soils because the volumetric heat capacities of water and ice are much larger than those of the soil particles and air. The volumetric heat capacity of water increases with $T$, while the volumetric heat capacity of ice decreases with $T$ (Figure 4). Therefore, in the unfrozen state $\left(T \geq 0^{\circ} \mathrm{C}\right)$, the larger the water content, the more significant the increase of the volumetric heat capacity with $T$. When $T$ drops below $0^{\circ} \mathrm{C}$, the larger the water content, the more the ice content in the frozen soil and the larger the decrease of the volumetric heat capacity (Figure 5(b)).

(3) The thermal diffusivity of water is much smaller than that of air, and the thermal diffusivity of ice is about ten times that of water. Therefore, in the initial freezing stage $\left(T \geq 0^{\circ} \mathrm{C}\right)$, the thermal diffusivities decrease with the increased water content. However, in the major phase transition zone $\left(0^{\circ} \mathrm{C}\right.$ $\left.>T \geq-3^{\circ} \mathrm{C}\right)$, the greater the water content, the more significant the effect of $T$ on the thermal diffusivity. In the frozen state $\left(T<-3^{\circ} \mathrm{C}\right)$, the thermal diffusivity of soils with high water content is larger than that of loess with low water content (Figure 5(c)). 


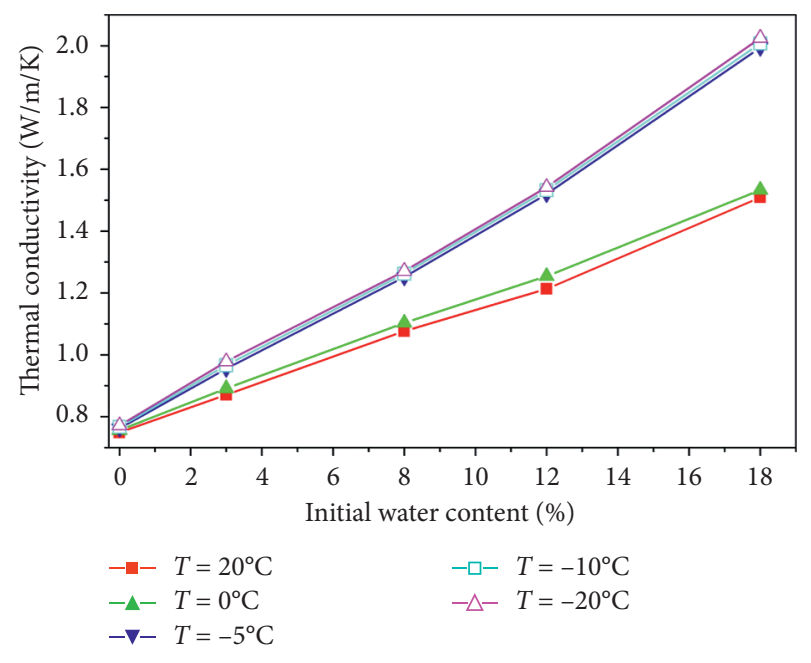

(a)

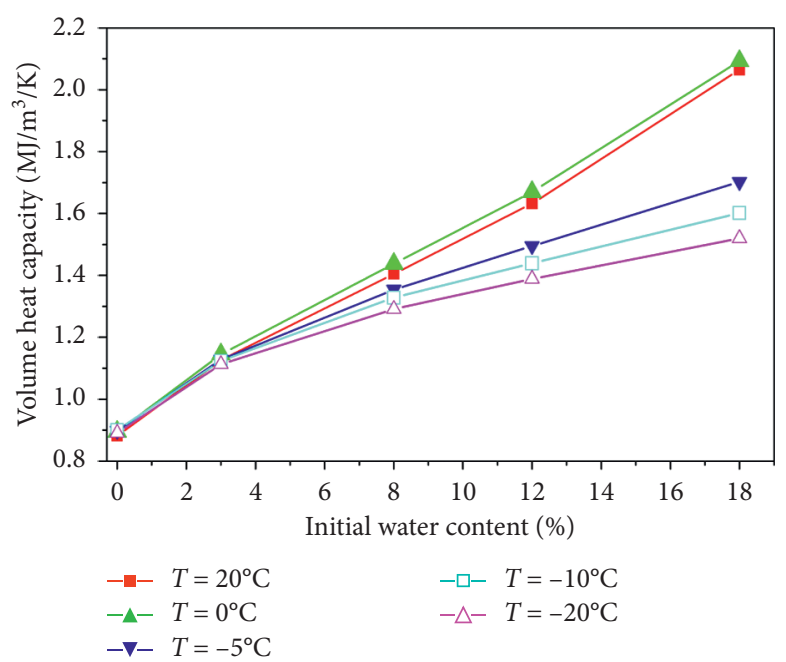

(b)

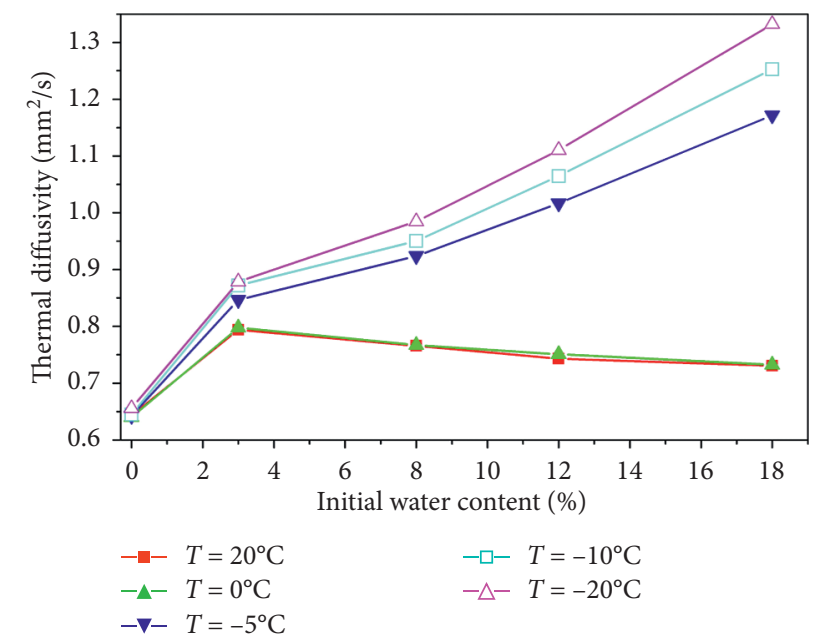

(c)

Figure 5: Thermal properties versus initial water content for soils under different temperatures. (a) Thermal conductivity, (b) volumetric heat capacity, and (c) thermal diffusivity.

\section{Discussion and Analysis}

4.1. Microstructure of Loess. The thermal properties of soils are influenced by many factors. Soil structure is one of the most important characteristics that affect the physical and mechanical properties including thermal conductivity [40]. Conduction heat transfer in wet soils occurs along all possible heat paths formed by the soil constituents, that is, solids, water, and air [31]. Therefore, the soil interparticle contacts play a critical role in conduction heat transfer [41]. Based on the microstructure analysis, this paper reveals the change mechanism of the thermal conductivity of soils before and after freezing. The SEM image in Figure 6(a) shows the microstructure of loess specimens. We can find that the soil particles are distributed disorderly and connected by cementation. Each particle has its own unique shape and irregular surfaces. In reality, soil particles with uneven surfaces vary in sizes and shapes, and the configuration of the contact spot between particles varies greatly (e.g., point contact) without smooth contact areas. The unique contact form results in a large number of pores of varying sizes and shapes within soils. The SEM image in Figure 6(a) was analyzed with Pore/Particle and Crack Analysis System (PCAS) [42]. The binary image (the threshold is 59) and result image of pores filled with color are shown in Figures 6(b) and 6(c). The pore area (small pores are removed) probability density of Figure $7(\mathrm{~d})$ and corresponding approximated power function curve are illustrated in Figure $7(\mathrm{e})$. We can find that the probability distribution function can well describe the distribution of pore size in soil samples.

The number of macrovoids is small, and the number of small pores increases greatly with the decrease of pore area. Because of the existence of these pores, substances such as air, water, and ice with thermal conductivities less than minerals become part of the heat transfer medium of soils. Thus, the heat transfer performance of the soil is smaller than that of the homogeneous minerals. Furthermore, the 

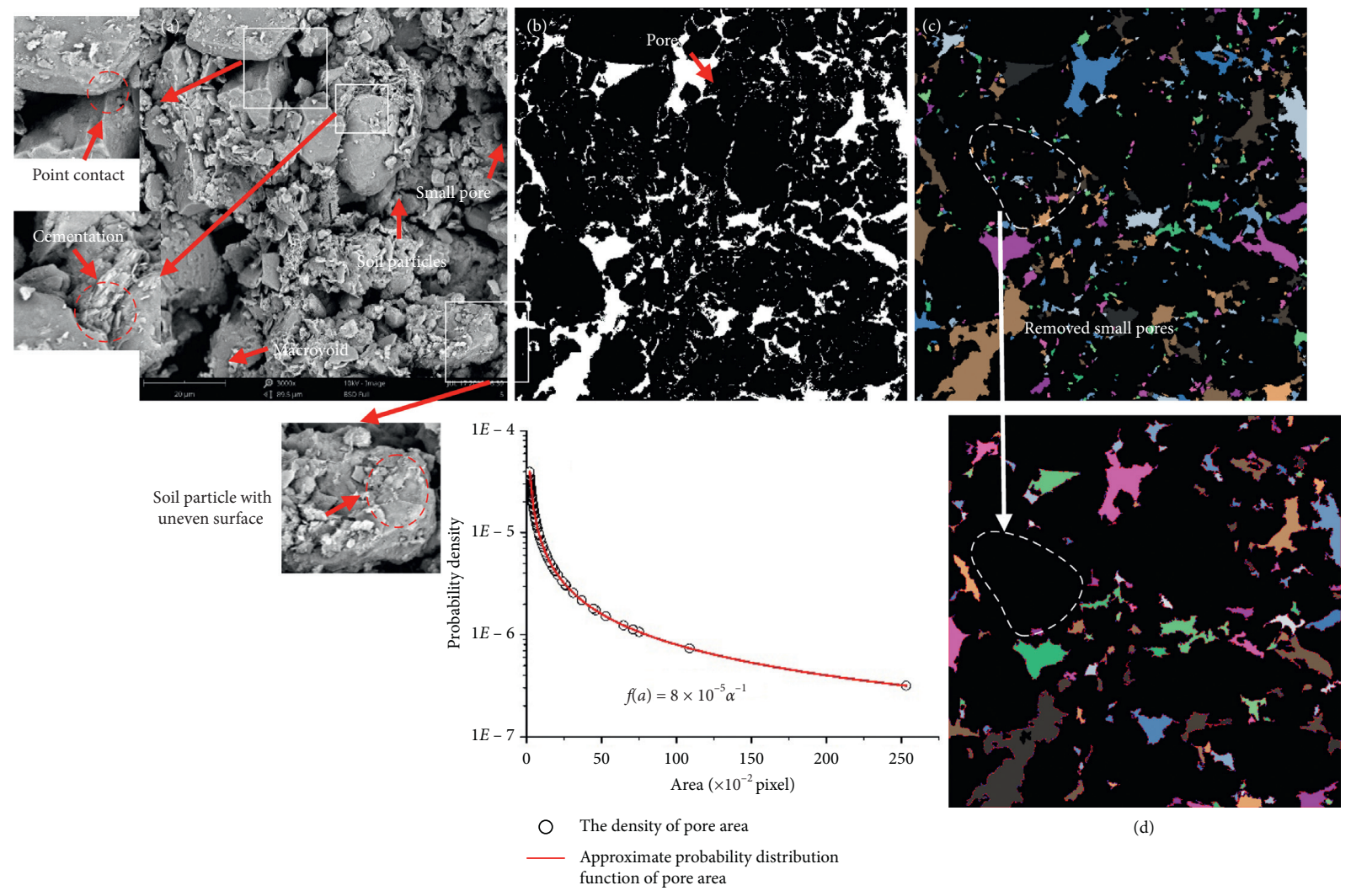

(d)

(e)

FIGURE 6: Original SEM image and PCAS proceeded images. (a) Original SEM image $(\times 3000,1024 \times 1026$ pixels, resolution 11.46 pixels/ $\mu \mathrm{m})$ of loess specimens. (b) Binary image (the threshold is 59). (c) Pore characterization with a minimum area of 20 pixels. (d) Pore characterization with a minimum area of 200 pixels (small pores are removed). (e) The probability density of pore area is approximated by a power function.

irregular shape and disordered arrangement of soil particles increase the thermal contact resistance (TCR), which further reduces the thermal conductivity of soils.

4.2. Thermal Conduction Mechanism of Loess. The change of soil temperature is actually caused by the conduction of heat in soil particles and heat-conducting media among soil particles. Due to the particularity of soil structure and the uneven distribution of heat-conducting media (Figure 6), the heat-conducting process is very complicated. Therefore, we make the following assumptions: (1) soil particles, pores, water, and air are evenly distributed in soils; (2) ice crystals are randomly generated in the pore water and evenly distributed in the process of water-ice phase transformation; (3) the complex process of heat conduction in soils is simplified as the process of heat conduction in a certain direction within heat transfer media. We obtain the heat transfer in soils under different states into one-dimensional steady-state heat transfer, as shown in Figure 7. $\Delta T_{P}$ is defined as the $T$ drop of heat when encountering soil pores, and $\Delta T_{x y}$ is defined as the $T$ drop between the heat input position of soil particle $x$ and the heat outflow position of soil particle $y$. There exist

$$
\begin{aligned}
\Delta T_{P} & =t_{A 2}-t_{B 1}, \\
\Delta T_{A A} & =t_{A 1}-t_{A 2}, \\
\Delta T_{B B} & =t_{B 1}-t_{B 2}, \\
\Delta T_{A B} & =\Delta T_{A A}+\Delta T_{P}+\Delta T_{B B}=t_{A 1}-t_{B 2},
\end{aligned}
$$

where subscripts $A$ and $B$ represent soil particles; $P$ represents the pore between $A$ and $B ; t_{A 1}, t_{A 2}, t_{B 1}$, and $t_{B 2}$ are temperatures of heat inflow and outflow positions of soil particles $A$ and $B$, respectively.

According to the theory of heat transfer, the heat passing through all sections is equal under steady-state heat transfer:

$$
Q=q S t=\lambda_{A} S t \frac{\Delta T_{A A}}{L_{A}}=\lambda_{P} S t \frac{\Delta T_{P}}{L_{P}}=\lambda_{B} S t \frac{\Delta T_{B B}}{L_{B}},
$$

where $Q$ and $q$ are the total heat flux and the heat flux density of the material, respectively; $S$ is the area of the material in the direction of heat transfer; $t$ and $L$ are heat transfer time and distance, respectively.

From equation (5), we can get 


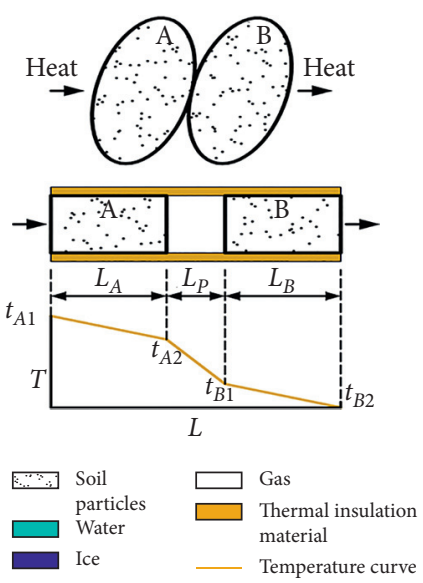

(a)
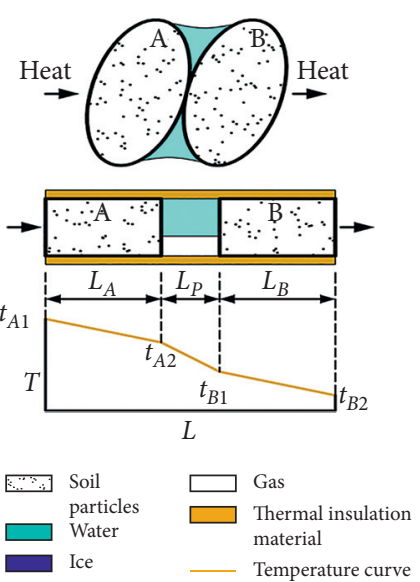

(b)
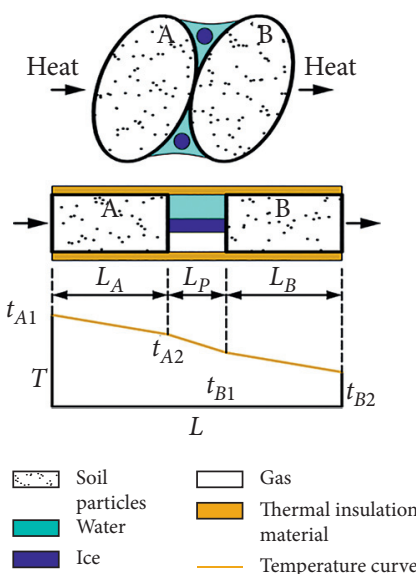

(c)

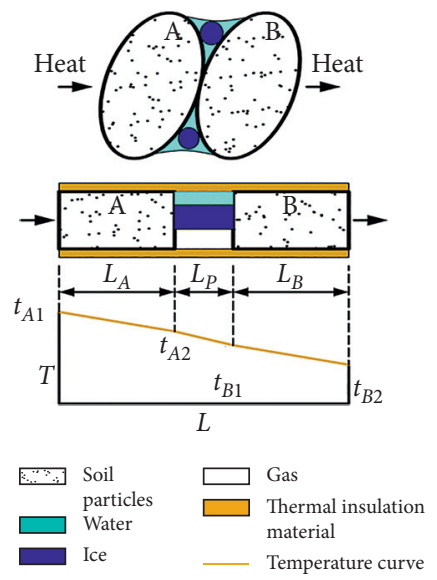

(d)

Figure 7: Schematic diagram of heat conduction between soil particles in different states: (a) dry soil; (b) wet soil at room (T); (c) early freezing stage of wet soil; (d) late freezing stage of wet soil.

$$
\begin{gathered}
\Delta T_{A A}=q \frac{L_{A}}{\lambda_{A}}, \\
\Delta T_{P}=q \frac{L_{P}}{\lambda_{P}}, \\
\Delta T_{B B}=q \frac{L_{B}}{\lambda_{B}} .
\end{gathered}
$$

Based on equations (4) and (6)-(8), the Tdrop caused by heat transfer is expressed as

$$
\Delta T_{A B}=q\left(\frac{L_{A}}{\lambda_{A}}+\frac{L_{P}}{\lambda_{P}}+\frac{L_{B}}{\lambda_{B}}\right) .
$$

We assume that heat transfer media such as air, water, and ice in the pores are evenly distributed. Based on the existing research results [3, 43-46], we can get three general models of pore thermal conductivity of frozen soil:

$$
\lambda_{P}=\varphi_{w} \lambda_{w}+\varphi_{i} \lambda_{i}+\varphi_{g} \lambda_{g}
$$

$$
\begin{aligned}
& \frac{1}{\lambda_{P}}=\frac{\varphi_{w}}{\lambda_{w}}+\frac{\varphi_{i}}{\lambda_{i}}+\frac{\varphi_{g}}{\lambda_{g}}, \\
& \lambda_{P}=\lambda_{w}^{\varphi_{w}} \lambda_{i}^{\varphi_{i}} \lambda_{g}^{\varphi_{g}},
\end{aligned}
$$

where $\varphi$ is the volume fraction; subscript $w, i$, and $g$ represent water, ice, and gas, respectively.

It is well known that heat transfer media between soil particles are different for different soils. For example, heat transfer media between wet soil (Figure 7(b)) particles are water and air and those of frozen soil (Figures 7(c) and 7(d)) particles are water, ice, and air, while that of dry soil (Figure $7(\mathrm{a})$ ) particles is only air. Combining equations (10)-(12), we can get $\lambda_{P}(\mathrm{a})<\lambda_{P}$ (b) $<\lambda_{P}(\mathrm{c})<\lambda_{P}$ (d), where $\mathrm{a}, \mathrm{b}, \mathrm{c}$, and d represent different soils (Figure 6). The thermal conductivity of soil particles increases with $T$ (section 3.1): $\lambda_{A}(\mathrm{a})=\lambda_{B}(\mathrm{a})=\lambda_{A}(\mathrm{~b})=\lambda_{B}(\mathrm{~b}) \leq \lambda_{A}(\mathrm{c}) \lambda_{B}(\mathrm{c}) \leq \lambda_{A}(\mathrm{~d}) \lambda_{B}(\mathrm{~d})$. Therefore, based on equation (9), we can get $\Delta T_{A B}(\mathrm{a})>$ $\Delta T_{A B}(\mathrm{~b})>\Delta T_{A B}(\mathrm{c})>\Delta T_{A B}(\mathrm{~d})$. This result can explain the macroscopic phenomenon that, compared with the unfrozen soil, the $T$ drop required for the frozen soil to transfer a certain amount of heat is smaller. 
TABLE 3: Thermal conductivities of the soil components.

\begin{tabular}{|c|c|c|c|c|c|c|c|}
\hline \multirow{2}{*}{$T\left({ }^{\circ} \mathrm{C}\right)$} & \multirow{2}{*}{$\rho_{d}\left(\mathrm{~g} / \mathrm{cm}^{3}\right)$} & \multirow{2}{*}{$c_{\mathrm{s}}(\mathrm{kJ} / \mathrm{kg} / \mathrm{K})$} & \multicolumn{3}{|c|}{$w_{i}(\%)$} & \multirow{2}{*}{$c_{\mathrm{w}}(\mathrm{kJ} / \mathrm{kg} / \mathrm{K})$} & \multirow{2}{*}{$c_{i}(\mathrm{~kJ} / \mathrm{kg} / \mathrm{K})$} \\
\hline & & & U3 & $\mathrm{U} 4$ & U5 & & \\
\hline 30 & & & 0 & 0 & 0 & 4.1785 & - \\
\hline 20 & & & 0 & 0 & 0 & 4.1819 & - \\
\hline 10 & & & 0 & 0 & 0 & 4.1922 & - \\
\hline 5 & & & 0 & 0 & 0 & 4.2015 & - \\
\hline 0 & & & 0 & 0 & 0 & 4.2177 & - \\
\hline-1 & & & 2.70 & 6.70 & 12.70 & - & 2.112 \\
\hline-2 & 1.32 & 0.768 & 3.76 & 7.76 & 13.76 & - & 2.101 \\
\hline-3 & & & 4.29 & 8.29 & 14.29 & - & 2.095 \\
\hline-5 & & & 4.82 & 8.82 & 14.82 & - & 2.079 \\
\hline-10 & & & 5.35 & 9.35 & 15.35 & - & 2.040 \\
\hline-15 & & & 5.66 & 9.66 & 15.66 & - & 2.001 \\
\hline-20 & & & 5.84 & 9.84 & 15.84 & - & 1.963 \\
\hline-30 & & & 6.12 & 10.12 & 16.12 & - & 1.881 \\
\hline
\end{tabular}

4.3. Calculation Model of the Volumetric Heat Capacity Frozen Soils. The volumetric heat capacity of unfrozen soils $S_{u}$ is the weighted arithmetic mean of the volumetric heat capacity of soil particles, water, and air [30]. Namely,

$$
S_{u}=c_{u} \rho_{u}=c_{s} \rho_{d}+c_{w} \rho_{w}+c_{g} \rho_{g},
$$

where $c$ is the specific heat capacity; subscript $u, s, w$, and $g$ represent unfrozen soil, soil particles, water, and gas, respectively; $\rho$ is the mass of a component of unfrozen soil per unit volume; and $\rho_{\mathrm{w}}=\rho_{d} w$.

The frost heave deformation of soils results from phase transition of water-ice with the decrease of $T$. It can be expressed as

$$
\begin{aligned}
& \varepsilon=\delta\left[\beta n S_{r} \mu-n\left(1-S_{r}\right)\right], \\
& \delta= \begin{cases}0, & (\mu \leq \chi), \\
1, & (\mu>\chi),\end{cases} \\
& \chi=\frac{1-S_{r}}{\beta S_{r}}, \\
& \mu=\frac{w_{i}}{w},
\end{aligned}
$$

where $\varepsilon$ is the volume expansion ratio of the soil based on the original volume; $\delta$ is the step function to determine whether the frost heave occurs; $\beta$ is the expansion coefficient of water-ice phase transition; namely, $\left(\rho_{\mathrm{w}} / \rho_{i}\right)-1 ; n$ and $S_{r}$ are the initial porosity and saturation of the soil; $\mu$ is the proportion of water that has been transformed; $w_{i}$ is the ice content of frozen soils.

For saturated soil $\left(S_{r}=1\right)$ in the initial state, based on equations (14) and (15), the volume expansion ratio of soils is expressed as

$$
\varepsilon=\beta n \mu .
$$

The calculation formula of volume heat capacity of frozen soils is as follows:

$$
S_{f}=\frac{c_{f} \rho_{u}}{1+\varepsilon}=\frac{c_{s} \rho_{s}+c_{w} \rho_{s}\left(w-w_{i}\right)+c_{i} \rho_{s} w_{i}+c_{g} \rho_{g}}{1+\varepsilon},
$$

where subscript $f$ represents frozen soil.

Based on equations (14)-(17) and (19), we can calculate the volumetric heat capacity of soils by testing the unfrozen water content. If we ignore the contribution of air to the volumetric heat capacity of frozen soil and $S_{r}$ or $\mu$ is small enough $(\varepsilon=0)$, equation (19) can be simplified as

$$
S_{f}=c_{s} \rho_{d}+c_{w} \rho_{d} w-\rho_{d} w_{i}\left(c_{w}-c_{i}\right) .
$$

If we ignore the contribution of air to the thermophysical properties of frozen soils and the soil is completely frozen $(\mu$ $=1$ ), equation (19) can be simplified as

$$
S_{f}=\frac{c_{s} \rho_{d}+c_{i} \rho_{d} w}{1+\varepsilon} \text {. }
$$

Equation (20) is used to calculate $S_{f}$ of soil at different temperatures, taking loess samples with initial $w$ of $8 \%, 12 \%$, and $18 \%$ as examples. The values of calculation parameters are shown in Table 3, and the specific heat capacity of water and ice is determined according to Figure 4. When the temperature is below $0{ }^{\circ} \mathrm{C}$, the specific heat capacity of unfrozen water is $4.2117 \mathrm{~kJ} / \mathrm{kg} / \mathrm{K} . w_{i}$ of frozen soils at different temperatures is calculated according to [47].

The calculated results from the model for the volumetric heat capacity of soils with different initial $w$ are shown in Figure 8. From the figure, it can be found that the change trend of the calculated values and the test results in the freezing process is consistent, which shows that the model can reflect the influence of $T$ on the volumetric heat capacity of soils. Figure 9 is the difference values between the calculated values and the tested results. We can find that when $T$ is above $0^{\circ} \mathrm{C}$, the difference values are smaller, and when $T$ is below $0^{\circ} \mathrm{C}$, the difference values are larger and positively correlated with the initial $w$ of soils. Moreover, with the decrease of freezing temperature, the difference values decrease gradually. For example, when $T$ drops from $-0.5^{\circ} \mathrm{C}$ to $-10^{\circ} \mathrm{C}$, the difference value of the sample with the initial $w$ of 


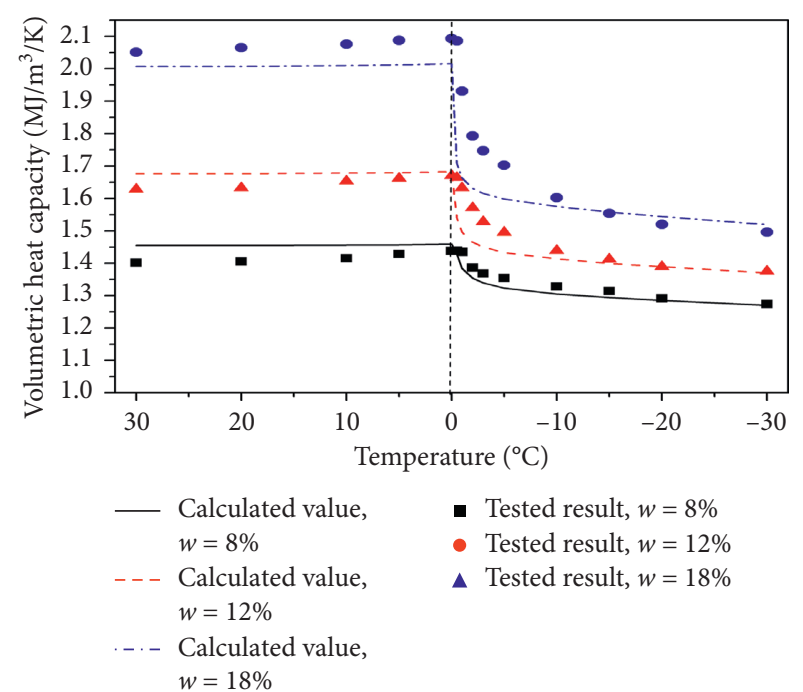

FIGURE 8: Comparison between the tested results and the calculated values.

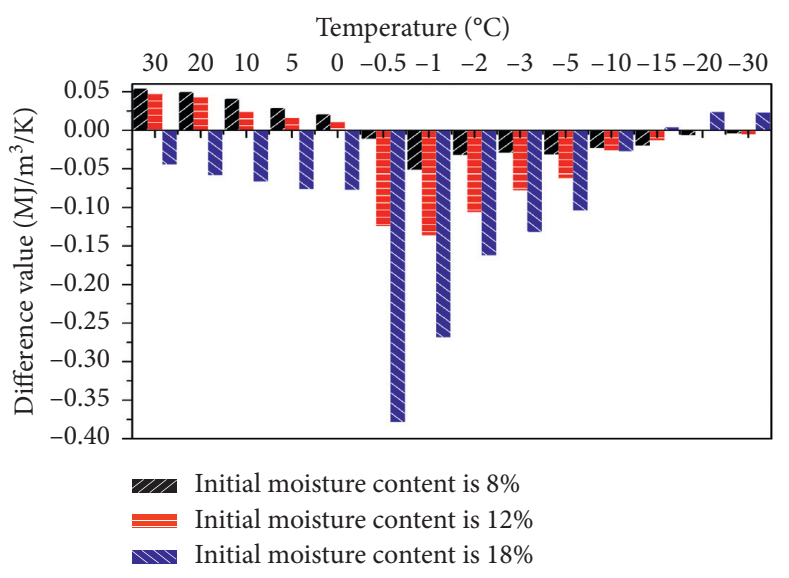

Figure 9: Difference values between the calculated values and the tested results.

$18 \%$ decreases from $0.378 \mathrm{MJ} / \mathrm{m}^{3} / \mathrm{K}$ to $0.026 \mathrm{MJ} / \mathrm{m}^{3} / \mathrm{K}$. The difference between the tested results and the calculated values of unfrozen soils may be due to the fact that the calculation model does not involve the thermal expansion and cold contraction deformation of soils and the change of thermal properties of soil particles with $T$. However, the difference in frozen soils may be due to the water migration during freezing, which results in the water content of the soil near the test probe greater than the initial water content. Therefore, the model is available to soils because of its simple form.

All in all, the above research shows that, compared with the unfrozen soil, the frozen soil has larger thermal conductivity, smaller volume heat capacity, and larger thermal diffusion coefficient; that is, cooling enhances the ability of soils to transfer heat. When the external environment cools down, the ice-water phase transition will occur, which will significantly improve the heat transfer and diffusion ability of soils. Moreover, in case of rain and snow, the increase of water content further accelerates the conduction and diffusion of heat. Therefore, the rise and fall of soil temperature is more significant, which is easy to cause freeze-thaw cycle of soils and has a negative impact on engineering.

\section{Conclusions}

This paper studied the change of thermophysical properties of loess with different water content during freezing. And the mechanism of change is given from the perspective of phase transformation and soil structure. The calculation model of volume heat capacity for frozen soil is established. Some conclusions can be drawn based on these studies as follows:

(1) The thermal properties of loess show a certain regularity with temperature during the freezing process, which can be divided into three stages. In the major phase transition zone, the variation of the thermal properties of loess with temperature is the most significant. And the thermal diffusivity increases sharply with the significant increase of thermal conductivity and the rapid decrease of volumetric heat capacity.

(2) Moisture content not only increases the thermal conductivity and volume heat capacity of loess but also makes the influence of temperature on the thermophysical parameters more significant. Furthermore, the larger the water content, the smaller the thermal diffusivity of soils at room temperature and the greater the effect of temperature on it.

(3) The effect of temperature on thermal properties of soils is mainly due to the phase transition of water-ice, followed by the change of thermal properties of heat transfer media such as soil particles, water, ice, and air with temperature. Increasing the water content reduces the contact thermal resistance between soil particles, thus changing the thermal properties of soils.

(4) Based on the weighted arithmetic mean model of soils at room temperature and considering the frost heave characteristics of soils, the calculation model of volumetric heat capacity of frozen soils was established and verified by the test results.

\section{Data Availability}

The data generated and analyzed during the current study are available from the corresponding author upon reasonable request.

\section{Conflicts of Interest}

The authors declare that there are no conflicts of interest.

\section{Acknowledgments}

This work was supported by the National Natural Science Foundation of China (nos. 41272340 and 41702339) and the Key Scientific and Technological Innovation Team Program Funds for Shaanxi Province (no. 2016KCT-13). 


\section{References}

[1] J. L. Qi, J. M. Zhang, and Y. L. Zhu, "Influence of freezingthawing on soil structure and its soil mechanics significance," Chinese Journal of Rock Mechanics and Engineering, vol. 22, no. S2, pp. 2690-2694, 2003.

[2] Y. Lai, M. Zhang, and S. Li, Theory and Application of Cold Regions Engineering, Science Press, Beijing, China, 2009.

[3] X. Z. Xu, J. C. Wang, and L. X. Zhang, Frozen Soil Physics, Science Press, Beijing, China, 2010.

[4] L. H. Rasmussen, W. Zhang, J. Hollesen et al., "Modelling present and future permafrost thermal regimes in Northeast Greenland," Cold Regions Science and Technology, vol. 146, pp. 199-213, 2018.

[5] G.-y. Li, W. Ma, Y.-h. Mu, F. Wang, S.-z. Fan, and Y.-h. Wu, "Effects of freeze-thaw cycle on engineering properties of loess used as road fills in seasonally frozen ground regions, North China," Journal of Mountain Science, vol. 14, no. 2, pp. 356-368, 2017.

[6] H. Zhou, Y. C. Zhang, Z. Ze et al., "Changing rule of longterm strength of frozen loess cohesion under impact of freezethaw cycle," Rock and Soil Mechanics, vol. 35, no. 08, pp. 2241-2246+2254, 2014.

[7] T. M. Su, "Test and analysis of thermal properties of soil in Nanjing district," Chinese Journal of Rock Mechanics and Engineering, vol. 25, no. 6, pp. 1278-1283, 2006.

[8] B. Usowicz, J. Lipiec, J. B. Usowicz, and W. Marczewski, "Effects of aggregate size on soil thermal conductivity: comparison of measured and model-predicted data," International Journal of Heat and Mass Transfer, vol. 57, no. 2, pp. 536-541, 2013.

[9] Y. Dong, J. S. McCartney, and N. Lu, "Critical review of thermal conductivity models for unsaturated soils," Geotechnical and Geological Engineering, vol. 33, no. 2, pp. 207221, 2015.

[10] N. Lu and Y. Dong, "Closed-form Equationuation for thermal conductivity of unsaturated soils at room temperature," Journal of Geotechnical and Geoenvironmental Engineering, vol. 141, no. 6, Article ID 04015016, 2015.

[11] N. Zhang and Z. Wang, "Review of soil thermal conductivity and predictive models," International Journal of Thermal Sciences, vol. 117, pp. 172-183, 2017.

[12] T. Zhang, G. Cai, S. Liu, and A. J. Puppala, "Investigation on thermal characteristics and prediction models of soils," International Journal of Heat and Mass Transfer, vol. 106, pp. 1074-1086, 2017.

[13] M. Zhang, J. Lu, Y. Lai, and X. Zhang, "Variation of the thermal conductivity of a silty clay during a freezing-thawing process," International Journal of Heat and Mass Transfer, vol. 124, pp. 1059-1067, 2018.

[14] Z. L. Zhen, "Thermal conductivities of remolded and undisturbed loess," Journal of Materials in Civil Engineering, vol. 31, no. 2, Article ID 04018379, 2018.

[15] I. V. Nikolaev, W. H. Leong, and M. A. Rosen, "Experimental investigation of soil thermal conductivity over a wide temperature range," International Journal of Thermophysics, vol. 34, no. 6, pp. 1110-1129, 2013.

[16] Y. Xiao, "Gradation-dependent thermal conductivity of sands," Journal of Geotechnical and Geoenvironmental Engineering, vol. 144, no. 9, Article ID 06018010, 2018.

[17] D. Y. Jia, "Responses of soil moisture and thermal conductivity to precipitation in the mesa of the Loess Plateau," Environmental Earth Sciences, vol. 75, no. 5, p. 395, 2016.

[18] D. Barry-Macaulay, A. Bouazza, R. M. Singh, B. Wang, and P. G. Ranjith, "Thermal conductivity of soils and rocks from the Melbourne (Australia) region," Engineering Geology, vol. 164, pp. 131-138, 2013.

[19] G. Cai, T. Zhang, A. J. Puppala, and S. Liu, "Thermal characterization and prediction model of typical soils in Nanjing area of China," Engineering Geology, vol. 191, pp. 23-30, 2015.

[20] W. A. Slusarchuk and G. H. Watson, "Thermal conductivity of some ice-rich permafrost soils," Canadian Geotechnical Journal, vol. 12, no. 3, pp. 413-424, 1975.

[21] N. H. Abu-Hamdeh, A. I. Khdair, and R. C. Reeder, "A comparison of two methods used to evaluate thermal conductivity for some soils," International Journal of Heat and Mass Transfer, vol. 44, no. 5, pp. 1073-1078, 2001.

[22] V. Balland and P. A. Arp, "Modeling soil thermal conductivities over a wide range of conditions," Journal of Environmental Engineering and Science, vol. 4, no. 6, pp. 549-558, 2005.

[23] D. Wu, Y. Lai, and M. Zhang, "Heat and mass transfer effects of ice growth mechanisms in a fully saturated soil," International Journal of Heat and Mass Transfer, vol. 86, pp. 699-709, 2015.

[24] Y. Kojima, J. L. Heitman, K. Noborio, T. Ren, and R. Horton, "Sensitivity analysis of temperature changes for determining thermal properties of partially frozen soil with a dual probe heat pulse sensor," Cold Regions Science and Technology, vol. 151, pp. 188-195, 2018.

[25] W. O. Smith, "The thermal conductivity of dry soil," Soil Science, vol. 53, no. 6, pp. 435-460, 1942.

[26] W. Woodside and J. H. Messmer, "Thermal conductivity of porous media. I. Unconsolidated sands," Journal of Applied Physics, vol. 32, no. 9, pp. 1688-1699, 1961.

[27] V. R. Tarnawski, T. Momose, and W. H. Leong, "Assessing the impact of quartz content on the prediction of soil thermal conductivity," Géotechnique, vol. 59, no. 4, pp. 331-338, 2009.

[28] O. Johansen, Thermal Conductivity of Soils, Cold Regions Research and Engineering Lab Hanover NH, Hanover, NH, USA, 1977.

[29] L. G. Neradovskii, "Calculation of the effective volume heat capacity from the wave characteristics of frozen soils," Measurement Techniques, vol. 56, no. 6, pp. 664-673, 2013.

[30] X. B. Tu and F. C. Dai, "Analytical solution for one-dimensional heat transfer Equationuation of soil and, evaluation for thermal diffusivity," Chinese Journal of Geotechnical Engineering, vol. 30, no. 5, pp. 652-657, 2008.

[31] V. R. Tarnawski and W. H. Leong, "Advanced geometric mean model for predicting thermal conductivity of unsaturated soils," International Journal of Thermophysics, vol. 37, no. 2, p. 18, 2016.

[32] B. Li, W. Xu, and F. Tong, "Measuring thermal conductivity of soils based on least squares finite element method," International Journal of Heat and Mass Transfer, vol. 115, pp. 833-841, 2017.

[33] J. Lipiec, B. Usowicz, and A. Ferrero, "Impact of soil compaction and wetness on thermal properties of sloping vineyard soil," International Journal of Heat and Mass Transfer, vol. 50, no. 19-20, pp. 3837-3847, 2007.

[34] G. Hu, L. Zhao, X. Wu et al., "New Fourier-series-based analytical solution to the conduction-convection equation to calculate soil temperature, determine soil thermal properties, or estimate water flux," International Journal of Heat and Mass Transfer, vol. 95, pp. 815-823, 2016.

[35] N. Zhang, X. Yu, and X. Wang, "Use of a thermo-TDR probe to measure sand thermal conductivity dryout curves (TCDCs) and model prediction," International Journal of Heat and Mass Transfer, vol. 115, pp. 1054-1064, 2017. 
[36] J. Côté and J.-M. Konrad, "A generalized thermal conductivity model for soils and construction materials," Canadian Geotechnical Journal, vol. 42, no. 2, pp. 443-458, 2005.

[37] T. Kozlowski, "Some factors affecting supercooling and the equilibrium freezing point in soil-water systems," Cold Regions Science and Technology, vol. 59, no. 1, pp. 25-33, 2009.

[38] H. Bing and W. Ma, "Laboratory investigation of the freezing point of saline soil," Cold Regions Science and Technology, vol. 67, no. 1-2, pp. 79-88, 2011.

[39] Y. Han, Q. Wang, Y. Kong et al., "Experiments on the initial freezing point of dispersive saline soil," Catena, vol. 171, pp. 681-690, 2018.

[40] O. T. Farouki, Thermal properties of soils, Trans Tech Publications, Zurich, Switzerland, 1986.

[41] T. S. Yun and J. C. Santamarina, "Fundamental study of thermal conduction in dry soils," Granular Matter, vol. 10, no. 3, pp. 197-207, 2008.

[42] C. Liu, B. Shi, J. Zhou, and C. Tang, "Quantification and characterization of microporosity by image processing, geometric measurement and statistical methods: application on SEM images of clay materials," Applied Clay Science, vol. 54, no. 1, pp. 97-106, 2011.

[43] R. W. Zimmerman, "Thermal conductivity of fluid-saturated rocks," Journal of Petroleum Science and Engineering, vol. 3, no. 3, pp. 219-227, 1989.

[44] W. M. Liu, P. He, and Z. Zhang, "A calculation method of thermal conductivity of soils," Journal of Glaciology and Geocryology, vol. 24, no. 6, pp. 770-773, 2002.

[45] H. F. Zhang, "Heat conduction and heat storage characteristics of soils," Applied Thermal Engineering, vol. 27, no. 2-3, pp. 369-373, 2007.

[46] X. J. Tan, "A new method to study thermal conductivity of geomaterials considering phase change," Rock and Soil Mechanics, vol. 31, no. 2, pp. 70-75, 2010.

[47] General Administration of Quality Supervision, Inspection and Quarantine of the People's Republic of China, Code for Engineering Geological Investigation of Frozen ground, p. 131P, General Administration of Quality Supervision, Inspection and Quarantine of the People's Republic of China, Bingjing, China, 2014. 